\title{
EL PAISAJE INTERMEDIO: ENTRE LO URBANO Y LO RURAL. UNA FRANJA DE TRANSICIÓN
}

TomÁs NeU*

\section{Resumen}

El paisaje intermedio es aquel suelo ubicado en las periferias de las ciudades que permanece vacío, no es urbano ni rural y debe ser intervenido para evitar que la informalidad y la fragmentación antecedan a lo ordenado y planificado. Este debe propiciar que el tejido urbano y social fluya sin que exista una discontinuidad desde las centralidades hacia la periferia urbana. Es un espacio que debe incorporarse siempre y cuando los gobiernos locales aseguren la adecuada prestación de servicios y equipamientos comunitarios.

La resolución del paisaje intermedio busca la continuidad y transición jerárquica y armónica entre tejidos urbanos para resolver divergencias e inequidades, y anticipar oportunidades. Existen varios ejemplos de proyectos urbanos que han logrado enfrentar el indiscriminado crecimiento urbano en estas áreas consideradas como vacías, generando enclaves con positivas connotaciones dentro del paisaje natural, cultural y la tradición urbana, que aportan a la consolidación de la expansión de las ciudades de manera equilibrada.

Palabras clave: paisaje intermedio, paisaje urbano, paisajismo urbano, paisaje natural y cultural.

* Maestría en Estudios y Gestión del Desarrollo. Subgerente fOMAG SA, Bogotá (Colombia). [tomasneu@gmail. com]

Recibido: 29 de junio de 2016 / Modificado: 17 de agosto de 2016 / Aceptado: 1 de septiembre de 2016

Para citar este artículo

Neu, T. (2016). El paisaje intermedio: entre lo urbano y lo rural. Una franja de transición. opera, 19, pp. 55-81.

DOI: http://dx.doi.org/10.18601/16578651.n19.05 


\section{MIDDLE LANDSCAPE: BETWEEN URBAN AND RURAL. A TRANSITION STRIP}

\section{Abstract}

An intervention on the middle landscape, that land of urban peripheries that is neither urban nor rural, should take place to avoid the informality and fragmentation setting in before orderly and planned development. Such an intervention should allow the urban and social fabric to flow without discontinuity from central urban areas right through to peripheries. Cities must incorporate the latter if, and only if, local governance ensures the provision of community services and infrastructure.

Urban and social fabric continuity, despite differences, inequalities and anticipating opportunities must be the basis of hierarchical and harmonious transitions. Some urban projects have managed to solve limitless urban growth along these apparently void areas, allowing positive enclaves to emerge within the natural and cultural landscapes and urban traditions, which contribute to a balanced urban growth.

Key words: Middle landscape, urban, rural, urban landscape, natural and cultural landscapes.

José Arcadio Buendia, que era el hombre más emprendedor que se vería jamás en la aldea, habia dispuesto de tal modo la posición de las casas, que desde todas podia llegarse al río y abastecerse de agua con igual esfuerzo, y trazó las calles con tan buen sentido que ninguna casa recibia más sol que otra a la hora del calor...

Gabriel García Márquez, Cien años de soledad

\section{INTRODUCCIÓN}

El siguiente texto es una mirada al paisaje intermedio, un intento por definirlo y mostrar sus particularidades y posibilidades al ser intervenido. Es una revisión a la ciudad como un ente vivo que se transforma, muta y que se deja, también, moldear.

Desde finales del siglo xix, muchas ciudades del mundo empiezan a crecer y desbordarse impelidas por las necesidades creadas y generadas por la incipiente Revolución Industrial. Es para entonces cuando las ciudades absorben la población migrante del campo para involucrarla en sus medios de producción, se requieren vías para los medios de transporte y nuevas maneras de albergar esa población en aumento. La ciudad que sufre estos procesos requiere de modelos de organización y de la humanización del espacio para enfrentar los cambios.

Martín Santos (Andrés, 2015), en su prólogo a la edición del texto de Max Weber publicado en 1921 y reeditado por la editorial La Piqueta en 1987, denomina "la ciudad como máscara de una sociedad insolidaria”. Menciona ese "suelo organizado" y el "espacio humanizado" que se han convertido en "cementerios invisibles" cuando surgen los suburbios y olvida que el centro de la ciudad debe "asumir su prestigio" y, de alguna manera, también mantenerlo. Asumir este prestigio olvidado y dejado de lado, alude a la posibilidad de que cualquier ciudad pueda asumir y resolver situaciones de diversa índole y complejidad.

Los análisis cartográficos de las ciudades modernas permiten identificar áreas perifé- 
ricas que son consecuencia del proceso de expansión de una ciudad, que no alcanzan a ser definidas como urbanas, pero tampoco se consideran rurales; son terrenos sin un uso específico, áreas sobrantes. También se evidencian espacios cuya connotación hace referencia al vacío, un suelo ocioso dentro de la ciudad. Estas superficies serán definidas como el paisaje intermedio (Rowe, 1991; Poston, 1997).

El paisaje intermedio es, por tanto, un espacio en transición, expectante entre ese paso de lo vacío, hacia lo útil; de lo fragmentado, a ser parte funcional de la expansión y del devenir urbano. Forma parte de un engranaje que dentro de lo obvio, debe propiciar estrategias y consolidar nuevas necesidades de aquello que lo bordea y limita. Propicia la estructura de nuevos usos y formas como parte de la incorporación de suelo útil.

El diagnóstico del habitar debe conducir a la pregunta sobre el trato que las sociedades mantienen hacia los lugares y el tipo de transformaciones físicas que experimentan estos lugares para ejercer, sobre este interrogante, una influencia hacia el cambio (Toro, 2013). La ciudad debe fortalecer el tejido urbano hacia lo público, y la interrelación entre los habitantes de manera activa e incluyente.

¿Cómo abordar estas superficies para zurcir de nuevo la ciudad y mantener contextos de centro y periferia unidos? ¿Cómo moldear e intervenir desde lo físico-espacial el contexto natural o artificial para consolidar o fortalecer comunidades y enmendar esa ruptura que se ha generado entre lo urbano (lo fragmentado) y lo social (lo segregado)? ¿Cómo trabajar el vacío que se confabula entre lo urbano y lo rural? Ocho miradas a distintas intervenciones responden de alguna forma las anteriores cuestiones y, a la vez, ayudan a la comprensión de ese paisaje intermedio que se pretende definir.

\section{HACIA EL PAISAJE INTERMEDIO}

El paisaje intermedio podría definirse como las áreas fragmentadas urbano-rurales, zonas de periferia interurbanas en proceso de consolidación, que se van conurbando de manera planificada o informal. Podrían identificarse también como zonas intraurbanas, "bolsas" libres dentro de la ciudad misma, deterioradas por la desvalorización inmobiliaria, o abandonadas - como las antiguas áreas industriales o ferroviarias-, o los intersticios residuales. Estos espacios poseen características diferentes, tanto desde sus particularidades físicas y espaciales, como económicas; obedecen a opciones de desarrollo y a propuestas de consolidación, renovación o redesarrollo urbano.

Esta configuración espacial asume que "la estructura de intervención sobre el paisaje se resolverá [...] mediante la intersección, la superposición y la intermediación de estrategias" (Caron y Martínez, 2008, p. 4), que facilitarán la adecuada planificación y transformación del territorio; la definición y continuidad urbana, y la concreción arquitectónica (Lynch, 1985; Shane, 2005). De requerir gobernanza, voluntad política, competitividad y actuaciones sobre el ámbito urbano, habrá que asegurar calidad de vida; continuidad urbana y social, y un respeto hacia lo natural, lo sostenible y 
sustentable (Pillet, Cañizares y Ruiz, 2010; Escallón, 2014) ${ }^{1}$.

El paisaje intermedio es consecuencia directa del fenómeno del suburbio, del sprawl y de la metropolización ubicada entre lo urbano y lo rural, denominado como leapfrog o salto de rana por Rowe (1991), y requiere que se perciba como una franja de transición, resiliente y vital (Rowe, 1991; Poston, 1997; Waldheim, 2016). Este paisaje podría determinar una escala desde donde es "posible observar $[\ldots]$ la forma en que se entrecruzan e interrelacionan las variables sociales, naturales y humanas" (Salom, 2010, p. 115), para transformar un territorio específico. Como menciona Zoido, "si la ordenación del territorio tiene en cuenta el paisaje puede dar mayor claridad y profundidad a sus objetivos ambientales, sociales y económicos" (2010, p. 104).

Los cuestionamientos sobre cómo abordar el paisaje intermedio deberían dominar el quehacer del diseñador urbano, del paisajista y del arquitecto -entre otras de las disciplinas que participan en el tema urbano-. Es necesaria la apropiación y transformación de este como parte conmensurable del crecimiento o de la incorporación de tierra al proceso de consolidación urbana, para evitar que lo informal y fragmentado anteceda a lo ordenado y planificado; como bien lo dice Rowe, es pertinente "encontrar una poética apropiada para el paisaje intermedio y definir principios claros para su diseńo y su desarrollo" (1991, p. 1).

\section{APARICIÓN Y TRANSFORMACIONES DEL PAISAJE INTERMEDIO}

... la siembra del trozo de cordón umbilical en la raíz de un árbol, permite que los habitantes de esta zona mantengan virtudes mágicas por el resto de sus vidas y una hermandad profunda con su tierra.

Ombligados en Jurubirá, Colombia²

La ciudad se establece como un sistema de unidades territoriales que interactúan entre ellas (Camagni, 2005, p. XXII), usualmente basadas en un único centro que se policentriza de manera irracional duplicando funcionalidades (Rowe, 1991). El asunto de la desigualdad, el fraccionamiento y la segregación se acrecienta sin control y permisividad, generando espacialidades complicadas de administrar. Igualmente, hay una red de sistemas estructurantes (movilidad, ecología, ámbitos público y privado, etc.) que maneja el análisis de las ciudades de manera relacional, sistémica, distinta y complementaria al análisis tradicional (Lynch, 1984; Borja y Castells, 1997; Shane, 2005) donde, por ejemplo, la participación comunitaria en la toma de decisiones es fundamental (Rosales, 2007; Sánchez y Egea, 2013) (figura 1).

\footnotetext{
1 Miguel Panadero (2010) hace una diferenciación entre estos conceptos, por lo que se adoptan juntos. Para mayor claridad es indispensable revisar la definición de la RAE (pp. 58-60).

2 Corto documental, directores: Juan Camilo García y Juan Manuel Vásquez. Bogotá, 2015. Disponible en http://www.ombligados.com/
} 
FIGURA 1. LA CIUDAD SE POLICENTRIZA EN EL CRUCE DE CAMINOS QUE CONFORMAN CENTROS Y PERIFERIAS DE MANERA IRRACIONAL

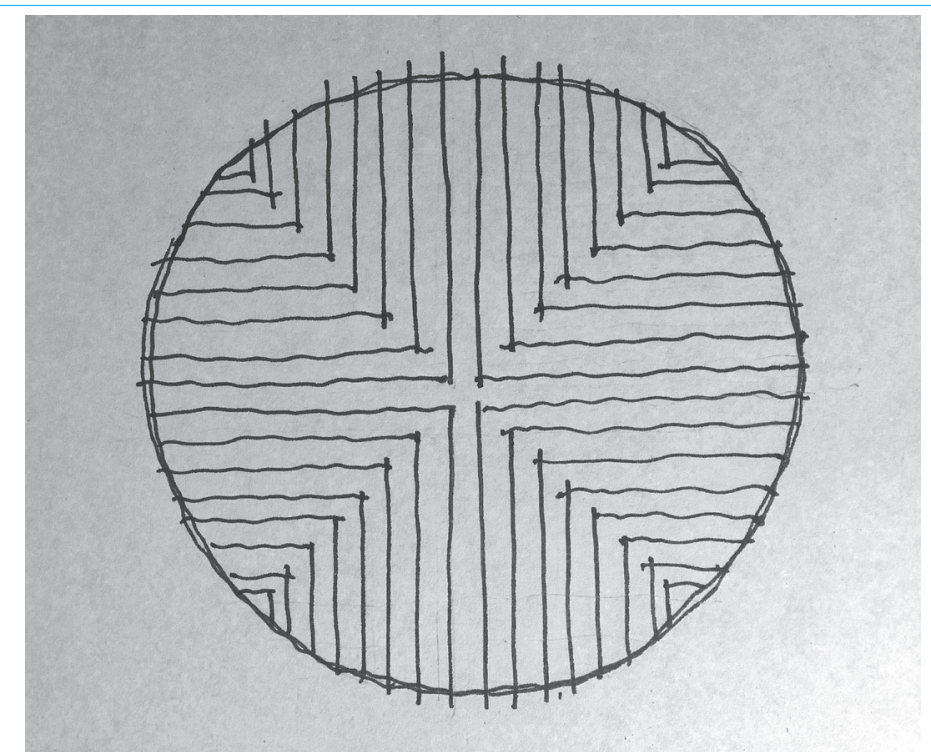

Fuente: representación del autor basado en similares gráficas.

A esta complejidad, los habitantes -de las periferias alejadas- escriben historia y cultura embebidos en conceptos como permanencia y pertenencia en lo local, donde se arraiga la necesidad de mantener la tradición de las arquitecturas, donde se teje lo social, lo comunitario. Se arman y requieren hitos y soportes formales e informales que enraízan el colectivo de lo imaginado para conformar espacialidades y reivindicar opciones (Lynch, 1984; Shane, 2005; Gouverneur, 2015). Es el lugar como expresión de lo cotidiano e inmaterial; no necesariamente resuelto.

La existencia y coexistencia de centralidades y periferias, según Castells (1976), es una cuestión "específica que capta los modos y las formas de organización social” (p. 94), basada en la aglomeración, accesibilidad e interacción espacial dirigida a lograr un desarrollo funcional apoyado en la producción, el comercio y el consumo (Camagni, 2005). En el argot técnico, la ciudad estructurada establece un tejido urbano cuya implantación espacial, unas veces zonificada o de libre crecimiento, acoge población, producción, transporte y consumo bajo un orden específico (Castells, 1976; Lynch, 1984; Rama, 1998; Krugman, 1998). La ciudad o sus partes - plazas, parques o calles, localidades o barrios- funcionan como una unidad espacial de consumo colectivo, escenario de lucha de clases, donde se arman imaginarios con sus complejidades, caos y divergencias (Batty y Longley, 1994). Debido a la modernidad, la ciudad del siglo xx amplió estas caracterizaciones hacia un crecimiento vertiginoso, ampliando límites y bordes para 
establecer un nuevo orden desde lo suburbano, de baja densidad (Choay, 1969), contrapuesto a lo informal, denso y segregado socialmente (Castells, 1976), o reordenando la ciudad, bajo aspectos de estructuras jerárquicas de vías y ejes de transporte (Lynch, 1984; Shane, 2005; Waldheim, 2016).

Para Lynch "la transformación original es el hecho de la aparición misma de la ciudad" (1985, p. 12), quedando implícito cualquier esfuerzo para mantener cohesionada a la sociedad que en ella habita. Así, y como principio fundamental debe, haber equilibrio, equidad y oportunidades en y alrededor de las ciudades (Blau, 1999; Poston, 1997).

\section{HACIA LA INTERVENCIÓN DEL PAISAJE INTERMEDIO}

... asi como el comerciante vive rico y muere pobre, al ganadero le ocurre lo contrario: vive pobre y muere rico, gracias a la valorización de la tierra que es en última instancia, lo que justifica la propiedad.

Roberto Urdaneta, Memorias de la Sabana

Las diversas formas de propiciar una mejor calidad de vida urbana requieren y buscan una participación, negociación y consenso colectivo donde, se espera, que una pluralidad social (equidad e inclusión social) sea la que usufructúe y se beneficie de estos cambios (Rosales, 2007). Esa simbiosis incor- pora conceptos -aun antagónicos de cierta manera- entre la arquitectura del paisaje (lo natural o aquello transformado para crear un paisaje cultural), el paisajismo arquitectónico (aquello que es estéticamente modificado o específicamente diseñado), y el paisajismo urbano donde lo verde es parte vital de lo urbano; donde la extensión rural es parte de lo urbano, y lo sostenible y sustentable adquiere importancia como parte de la relación urbanorural (Thompson, 2014).

Estas acciones deben emprenderse de manera interdisciplinaria desde la teoría urbana que instruye conceptos de estructura, identidad y significado. Estas, a su vez, están jerarquizadas y definidas bajo funcionalidades de planificación urbana, urbanismo, diseño urbano y arquitectura, como disciplinas que prefiguran la morfología de los enclaves urbanos (Lynch, 1985; Kostov, 1991; Waldheim, 2016). Waldheim menciona que "los orígenes del diseño urbano y la planificación se relacionan para producir el paisaje como arquitectura" (2016, p. 5) ${ }^{3}$; esto, en palabras de Lynch, es "un arte temporal [...]; a la ciudad se la ve con diferentes luces y en todo tipo de tiempo" (1984, p. 9), con lo cual se validan significados, pertenencias y permanencias urbanas. Incluso conlleva la importancia de pensar en renovación y rehabilitación de los ámbitos urbanos, desde las centralidades hacia las periferias, para mantener esas identidades $\mathrm{y}$ significados en los imaginarios de la sociedad que usufructúa esos espacios; involucra al paisaje intermedio como esa franja que permite

3 El autor de este artículo se permite traducir libremente citas en idioma inglés y alemán. 
un actuar sobre la tradición urbana y una contextualización del entorno (Martí, 2000).

Lo anterior exhorta a pensar y entender diferencias entre ideales comunitarios sobre la utilidad de la tierra que contrasta con el hecho de la propiedad privada, donde queda expectante la especulación y la utilidad de esta (Poston, 1997). Por ello, ante el desarrollo de las ciudades, la continuidad del tejido urbano y la incorporación del paisaje natural o intermedio como franja de transición -ojalá con multiplicidad de usos- es fundamental para evitar la fragmentación y la suburbanización.

Sobre la importancia y el significado que tiene el intervenir el paisaje, se examinarán ejemplos que, desde el paisaje natural o el paisaje cultural cohesionan y elaboran a partir de los vacíos. Son modelos que ordenaron el crecimiento de ciudades; disimiles en su historia y consolidación urbana, que propiciaron espacio público dentro de una arquitectura que los conforma y percibe nuevas formas de incluir intersticios invisibles convirtiéndolos en espacios simbólicos para distinguir nuevas realidades y resignificar otredades.

\section{PAISAJE INTERMEDIO E INTERVENCIONES}

Era como si el plano estuviera trazado sobre una hoja de caucho infinitamente flexible; las direcciones se torcian, las distancias se alargaban o acortaban y las formas grandes cambiaban tanto en relación con su proyección justa en escala, que al principio no se las podía

reconocer.

Kevin Lynch, La imagen de la ciudad

\section{Emerald Necklace, Boston, Estados Unidos}

Frederick Law Olmsted (1822-1903), botánico y periodista, propone para finales de 1870 , cuando Boston es ya una ciudad abigarrada y compleja, la creación de un sistema de parques en un lugar céntrico, del cual irradiaban brazos de tipo radial o lineal, regulares e irregulares hacia la ciudad, en dimensiones de 80 a $150 \mathrm{~m}$ de ancho, convirtiéndose estos en paseos o bulevares que se conectaban entre sí (Galeano, 2011). Los parques no serían globos de terrenos añadidos a la ciudad sino un corredor que integraba y relacionaba la ciudad y su entorno natural con sus características ecológicas.

El Emerald Necklace (figura 2), a lo largo de $11 \mathrm{~km}$, definió un par vial verde bordeado por viviendas y usos mixtos (hospitales, museos, escuelas), de baja densidad, como paseo en medio de un paisaje cambiante y pleno de contrastes.

El sistema conformado por Franklin Park, Arnold Arboretum, Jamaica Park, Olmsted Park, Riverway y Back Bay Fens, en un área de 200 hectáreas, incluía ríos, pantanos, bosques y terrenos donados por terratenientes. Las áreas de recreación y su forma de hacer parte y entrelazarse con la ciudad lo convirtió en uno de los primeros ejemplos de intervención de paisaje intermedio al generar una zona integrada que ya no es rural y se configura dentro de lo urbano (Beveridge y Rocheleau, 1998).

Esta representa hoy, luego de más de cien años, una opción de sostenibilidad urbana; es un gran parque urbano que conceptualizó no solo un tema técnico de manejo de aguas, 
FIGURA 2. F. OLMSTED - EMERALD NECKLACE, BOSTON, USA. EL EMERALD NECKLACE ES UN GRAN PARQUE URBANO CUYA GÉNESIS ESTUVO ENFOCADA EN MEJORAR LA CALIDAD DE VIDA EN LA CIUDAD QUE CRECÍA

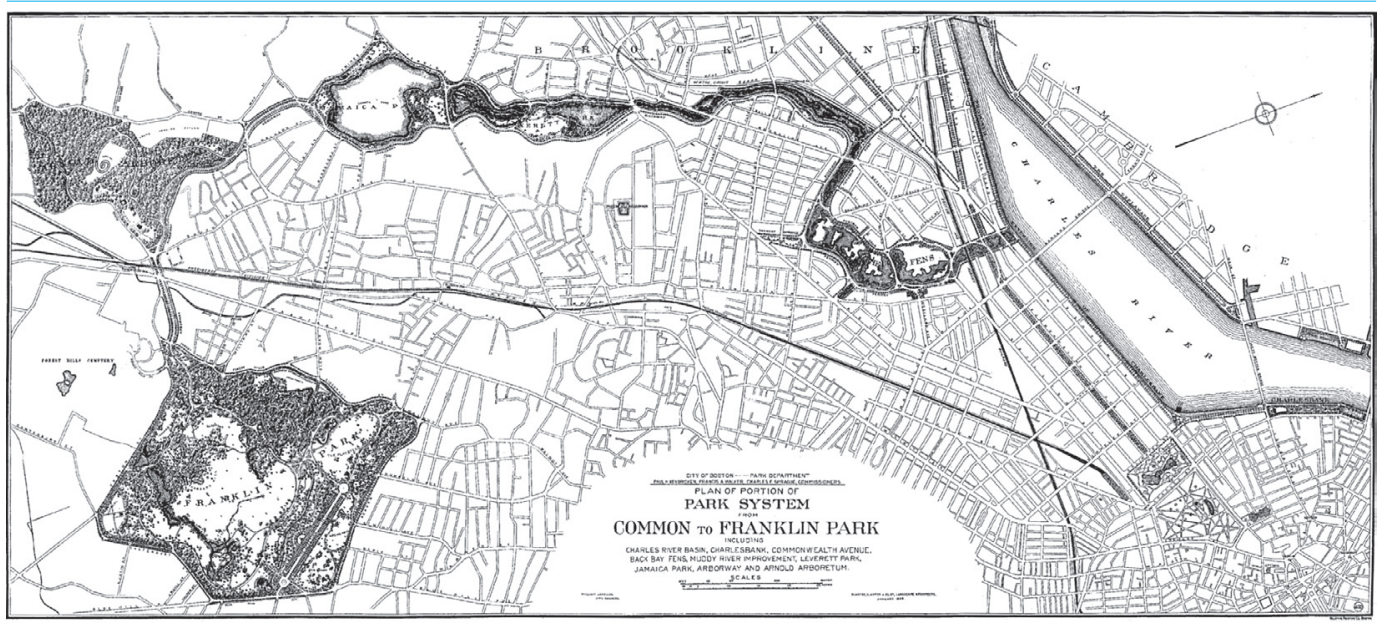

Fuente: Creative Commons. https://en.wikipedia.org/wiki/Public_domain.

sino un importante legado enfocado hacia una mejor calidad de vida, principio básico del pensamiento olmstediano.

La propuesta de Olmsted y la generación de este tipo de paisajes desdibuja la línea que reinterpreta la aplicación del diseño urbano y del diseño del paisaje para integrarla en una sola disciplina fusionada ${ }^{4} \mathrm{o}$ paisajismo urbano (Thompson, 2014) capaz de enfrentar geografías rotas; territorios divididos por franjas, por áreas amorfas de manera conmensurada. Es la transición del paisaje natural hacia el paisaje cultural, que asume parte del proceso de transformación territorial como imagen integradora, representando una transversalidad de acciones (Gómez, 2010; Gómez y Londoño, 2011).

\section{Siedlungen y Hof, Berlín, Alemania y Viena,} Austria

En los albores del siglo XIX, algunos arquitectos europeos propusieron nuevas $\mathrm{y}$ variadas formas para vivir en las ciudades en vertiginoso crecimiento. Se buscaba construir viviendas más eficientes, mejor iluminadas y, sobre todo, cómodas e higiénicas, bordeadas por jardines, parques y bosques. Apareció el interés por manejar lo privado, lo público y lo comunitario como parte de las transiciones espaciales. Para ello se promovieron laboratorios de vivienda, donde se analizaban, proponían y desarrollaban nuevas tipologías arquitectónicas (tipos de edificios, unidades habitacionales), y técnicas de construcción

$4 \quad$ La disciplina Landscape urbanism se puede traducir como paisajismo urbano. 
industrializadas y normalizadas (Blau, 1999; Martí, 2000).

La vivienda debía ser un elemento que mejorara y simplificara las condiciones de vida que se estaban gestando en la nueva sociedad industrial. Bajo estos parámetros se diseñaron y levantaron en Alemania y Austria las urbanizaciones para obreros conocidas como Siedlungen y Hof ${ }^{5}$, que contaban con lugares comunitarios, lavandería y comercio. Las viviendas a su vez podían tener cocinas y baños en su interior.

Las Siedlungen serán una interpretación de las ciudades jardín, propuestas para entonces en Inglaterra, donde "se demuestra la capacidad de la casa para engranarse en una organización colectiva sin perder su condición de célula autónoma" en ocasiones privada, dentro "de un hecho urbano en su conjunto" (Martí, 2000, p. 22).

Un modelo notable es Hufeisensiedlung (La Herradura) (figuras 3, 4 y 19) en Berlín, diseño de Bruno Taut y Martin Wagner, construida entre 1925 y 1930. La urbanización está conformada por grupos de viviendas cuyas fachadas paramentadas continuas, y un lenguaje arquitectónico diverso, combinan varias tipologías de vivienda uni y multifamiliar y consolidan un barrio de 1963 unidades habitacionales. El conjunto logra una arquitectura urbana densa, llena de coloridos contrastes y juegos volumétricos, matizada por solares para agricultura urbana que hace que toda la urbanización sea de baja densidad y contemple un paisaje generoso (Brenne, 2013).

Hoy las condiciones han cambiado y los solares otrora productivos son frondosos jardines. El conjunto combina espacios públicos con espacios comunitarios y privados aportando a la ciudad un entorno amable, arborizado y transitable, de altísima calidad. La preservación de este barrio ofrece actualmente la oportunidad para pensar en estos ejemplos de enclaves urbanos como intervenciones capaces de responder a la sostenibilidad, ofreciendo a las comunidades soluciones integrales. Así mismo, representan la idealización concreta de un modelo de ciudad sustentable.

En 1986, la Hufeisensiedlung fue inscrita como patrimonio nacional para apoyar su conservación y protección, y en 2008 la UNESCO declaró el conjunto como Patrimonio de la Humanidad.

En Austria, y en especial en Viena, para la misma época, se desplegaron proyectos similares. Tras el fin de la Primera Guerra Mundial, y con la desintegración del Imperio austrohúngaro, se proclamó la república de Austria. La capital se convirtió en estado federal de la nueva república democrática y en las elecciones de Viena (1919) el Partido Social Demócrata Obrero Austriaco dio inicio al periodo llamado la "Viena Roja" (Rotes Wien), tiempo durante el cual dentro del plan de vivienda pública se construyeron más de 65.000 unidades (Blau, 1999). Sello de un emblema, confirman

5 Las Siedlungen (Berlín) y los Hof (Viena) ejemplifican una similar tipología arquitectónica en cuanto a tamaño de la urbanización y los usos. Se diferencian en el manejo de la propiedad del suelo: en Viena, la mayoría son edificios multifamiliares donde la tierra es comunal y pertenece a la ciudad. 
FIGURA 3. HUFEISENSIEDLUNG, BERLÍN. PLANO URBANO (BRENNE, 2013, P. 90)

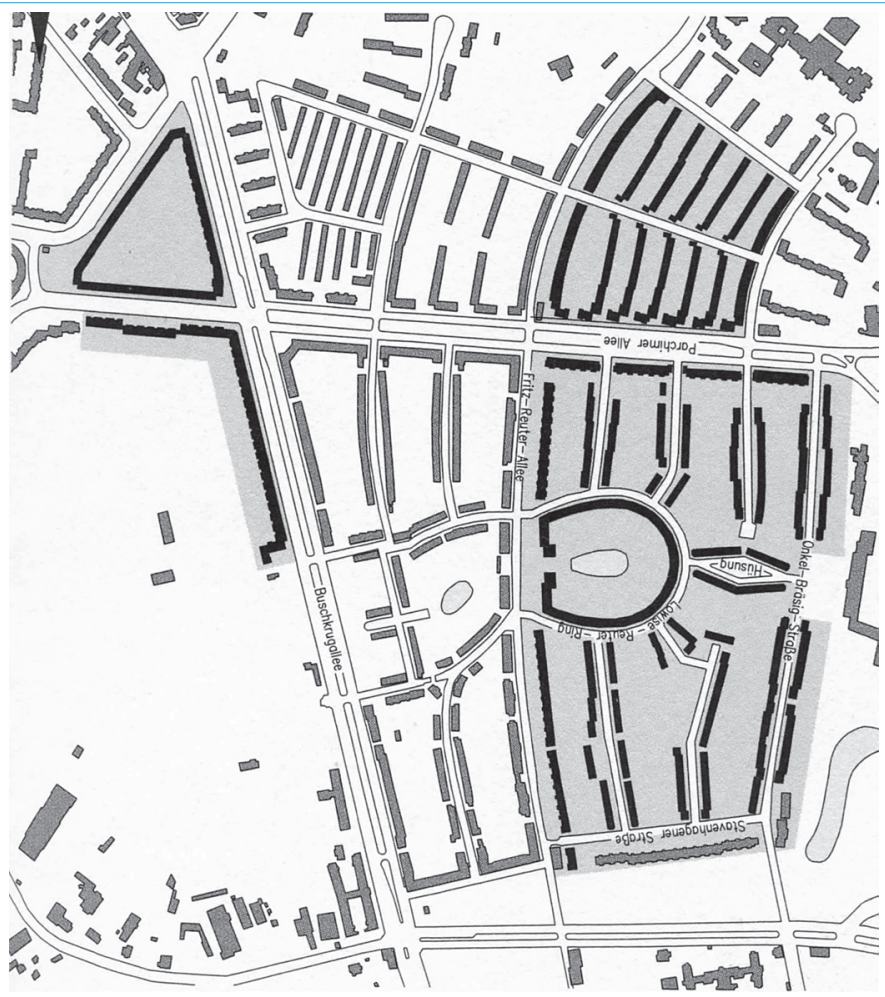

Fuente: http://www.modernes-berlin.de/republik/hufeisenf.htm

FIGURA 4. HUFEISENSIEDLUNG, BERLÍN

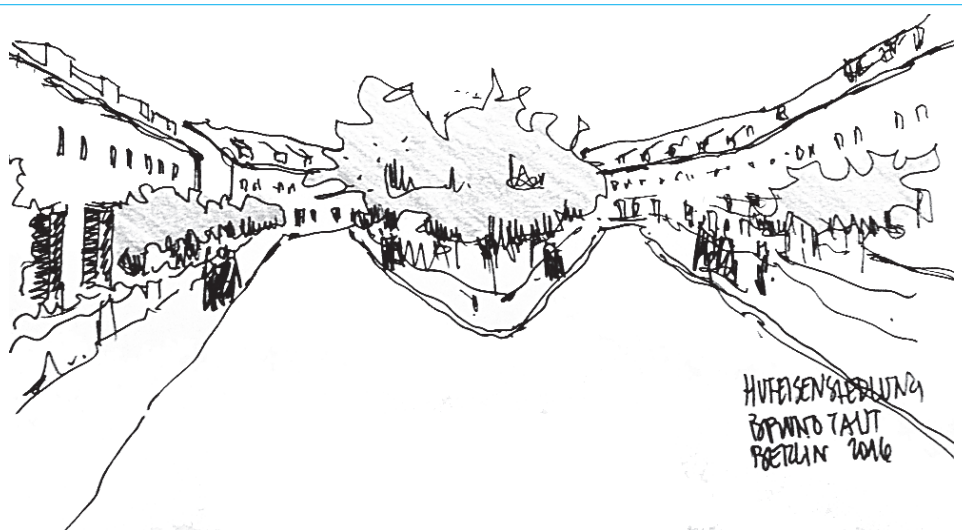


la importancia de una voluntad política unida a la responsabilidad pública.

En estos proyectos participaron entre otros, Adolf Loos (1870-1933), Heinrich Schmid (1885-1949) y Hermann Aichinger (1885-1962), Peter Behrens (1868-1940), Margarete Lihotzky (1897-2000), liderados por el ayuntamiento de la ciudad. El programa contempló, bajo el nombre de Gemeindebauten o vivienda social, la construcción de bloques perimetrales (Randverbauung), rellenos o in fill (Lückenverbauung), bloques superpuestos (Grosswonhnanlage) y urbanizaciones completas (Wohnviertel) que alteraron la tipología arquitectónica general de la ciudad (figura 5). Fueron innumerables las intervenciones que aún hoy perduran, y que son intervenidas para cumplir con nuevos estándares habitacionales requeridos hoy en día; edificios y viviendas se han adaptado con flexibilidad y rigurosidad al paso del tiempo manteniendo su vigencia.
El Rabenhof de Viena (figuras 6, 7 y 8) es un conjunto de edificios extenso, paramentado y sinuoso. Las fachadas conforman bloques de edificios hacia calles de barrio, mientras que en el interior aparecen plazas, escuelas y parques. Deambular por el proyecto es pasar por diversos ambientes uniformes (fachadas) y heterogéneos a la vez (volumetrías y espacios de diversa forma). Este proyecto se construyó entre 1925 y 1928 en la periferia a medida que los terrenos ocupados por barracas y asentamientos informales se liberaban. Era una respuesta dirigida a un desarrollo urbano específico de saneamiento y de complemento de un área intermedia en esa ciudad que estaba creciendo. Este proyecto contiene más de 1100 unidades de vivienda.

La experiencia al llegar a la estación de metro Kardinal-Nagel Platz, siguiendo por la avenida HainburgerStrasse, permite que el transeúnte se encuentre con una cinta de edificios que componen espacios públicos y

FIGURA 5. DIVERSOS TIPOS DE INTERVENCIÓN URBANA Y DE TIPOLOGÍAS ARQUITECTÓNICAS EN LA VIENA ROJA

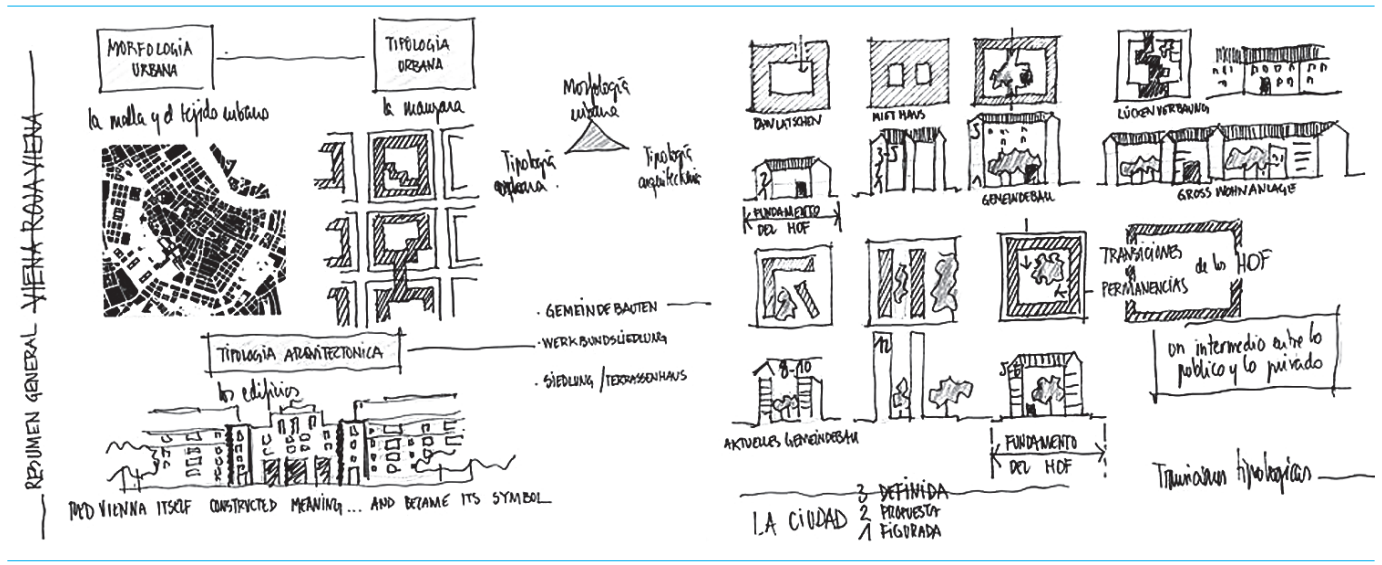

Fuente: dibujo del autor. 


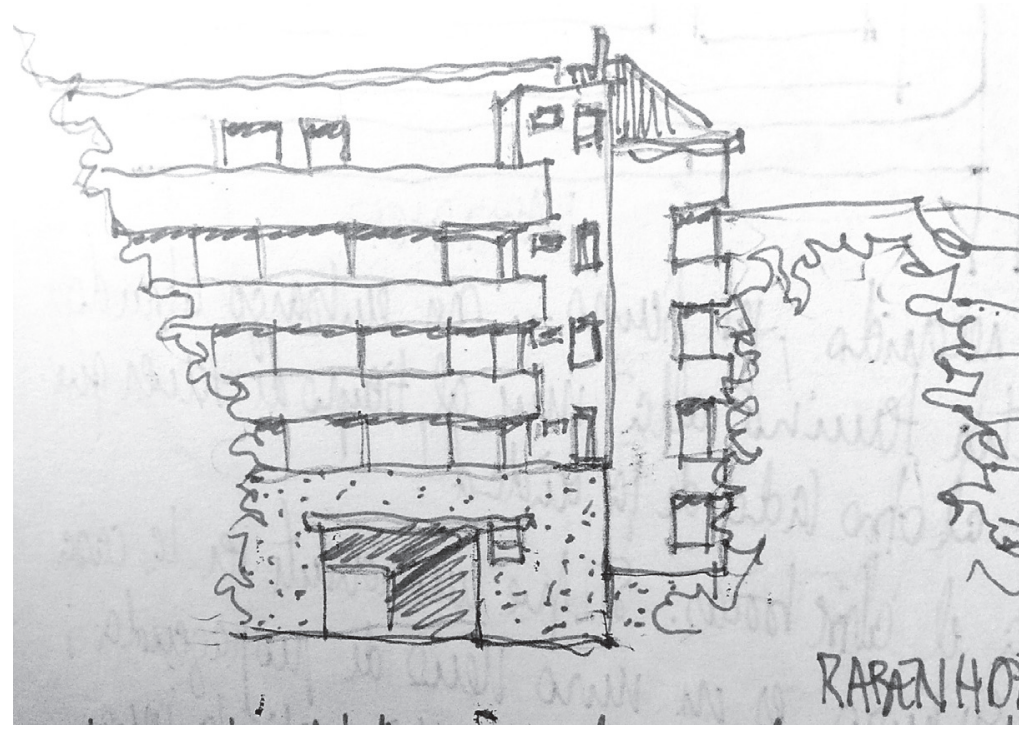

Fuente: dibujo del autor.

semipúblicos; plazas, parques, espacios peatonales, pasos vehiculares donde lo más interesante es la cinta de edificios sinuosamente extendida que arma una perspectiva que se pierde en la conformación de otros espacios. En palabras de Blau, "El efecto es difuminar los límites entre el interior y el exterior, de modo que el Hof y la ciudad, que reclaman el mismo derecho al dominio público de la calle, se fusionen y se conviertan en una sola entidad" (Blau, 1990, p. 298).

La paramentación de fachadas; la continuidad de las construcciones; el paso de los edificios sobre vías urbanas; las puertas arquitectónicas de proporciones magníficas, la arborización y los espacios de transición, son evidencia de ese zurcir la ciudad y la periferia a través de la intervención sobre un paisaje intermedio. Vale mencionar que este tipo de proyecto "se refiere a la concepción del hecho urbano en su conjunto" (Martí, 2000, p. 22), complementando y diversificando la estructura, y reinterpretando la ciudad-jardín suburbana al crear recintos.

\section{Parla del Este, España}

Abel Gil, geógrafo y especialista en ordenamiento del territorio y desarrollo sostenible, reseña un proyecto reciente de urbanización en el municipio madrileño de Parla, en España. Titula su escrito Los nuevos retos en la creación de ciudad: integrar los paisajes previos. En el anota:

...en ámbitos urbanos o metropolitanos los estudios de los paisajes, tienden a centrarse en los espacios valiosos aún sin urbanizar o en la ciudad ya construida, pero sin 
FIGURA 7. RABENHOF, VIENA. EL TRANSEÚNTE SE ENCUENTRA CON UNA CINTA DE EDIFICIOS QUE COMPONEN ESPACIOS PÚBLICOS Y SEMIPÚBLICOS: PLAZAS, PARQUES, ESPACIOS PEATONALES, PASOS VEHICULARES, PERO LO MÁS INTERESANTE ES LA CINTA DE LOS EDIFICIOS SINUOSAMENTE EXTENDIDA

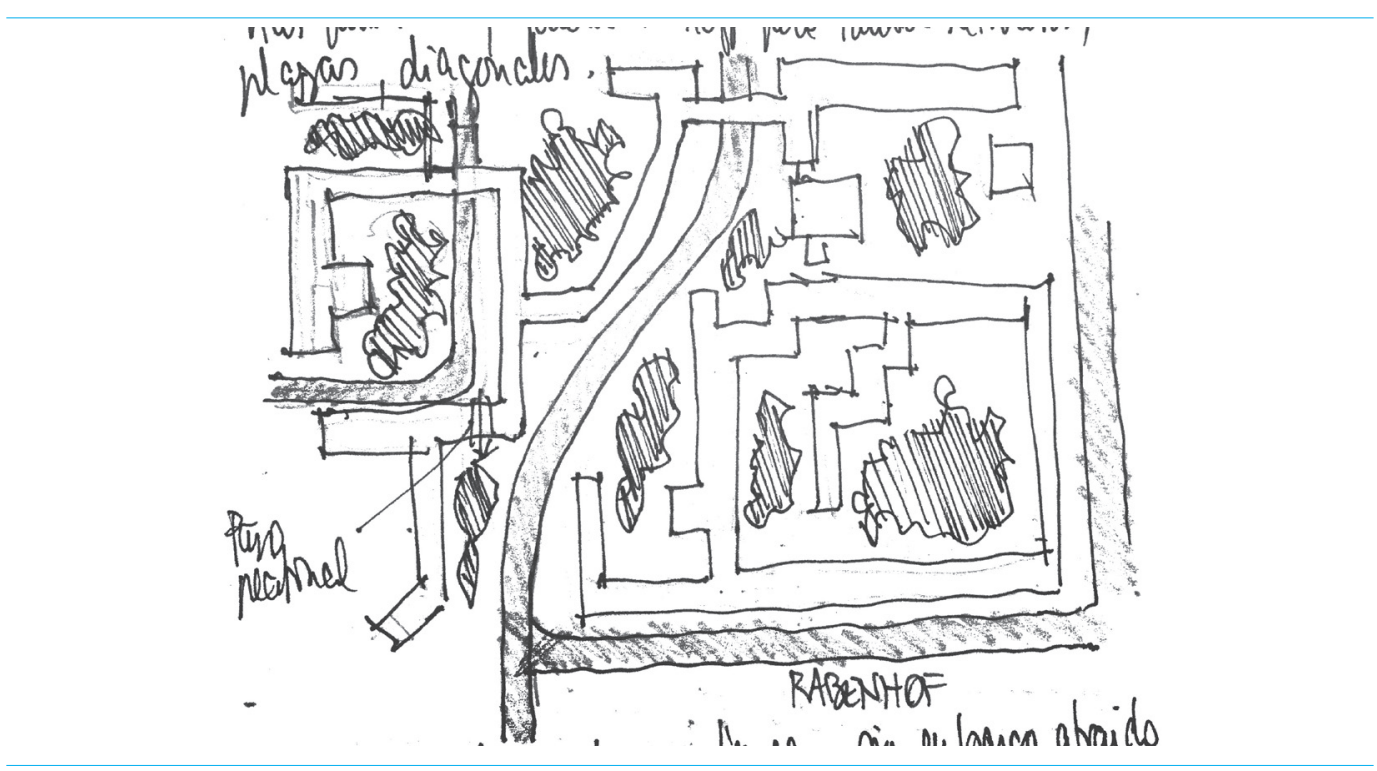

Fuente: dibujo del autor.

FIGURA 8. RABENHOF, VIENA. PLAZA-PARQUE AL LADO DE LA ESCUELA Y EDIFICIOS

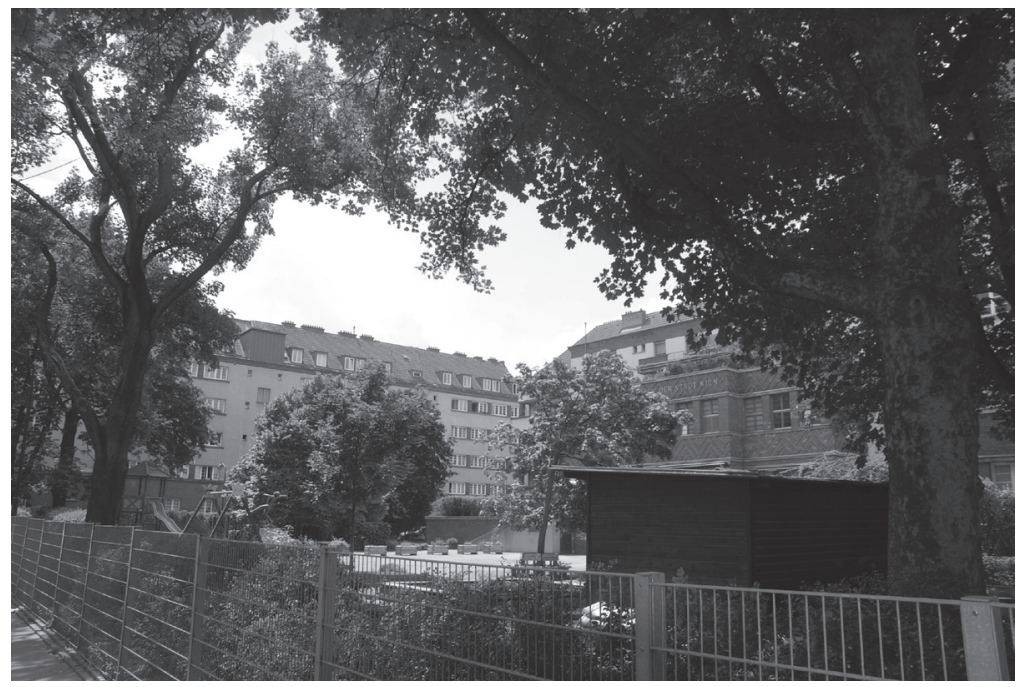

Fuente: foto del autor. 
llevar a cabo una relación entre ambos, de los espacios de borde. El cambio perceptual entre ambos espacios es brusco, cuando la proliferación de la urbanización dispersa y los crecimientos en manchas de aceite han ocasionado una transición funcionalmente diluida.

\section{$[\ldots]$}

...se debe plantear la creación de una nueva ciudad no desde un plano en blanco, sino sobre un territorio previo con relieve y morfología propia y singular, con un alto potencial de transformarse en un espacio urbano único y diferenciado que pueda ser habitado por una sociedad con las mismas características.

El ejemplo que toma Gil, ilustrado en las figuras 9 y 10, de Parla del Este, podría servir para un análisis que permita acometer con éxito un desarrollo homogéneo y claro de un paisaje intermedio.

En este proyecto, sobre un espacio limitado, bordeado y controlado, se inició un plan a mediano y largo plazo, donde se establecieron continuidades viales, áreas de ocupación y diversos usos. Mediante la conformación de parques y zonas verdes se cosió la ciudad, entretejiendo sus elementos previos, comprendiendo el territorio y su continuidad. La intención es la de trabajar de los bordes hacia adentro, definidos estos por un tejido urbano y un sistema vial (incluso sobre lo preexistente).

El resultado del proceso de esta urbanización en 2016 muestra el límite del parque a la izquierda (figura 11) y el parque entre el casco "antiguo y el nuevo", que conciben centralidades y vitalizan la unión. Gil afirma que en este proyecto se crearon
FIGURA 9. TERRENOS AGRÍCOLAS, PARLA DEL ESTE, ESPAÑA

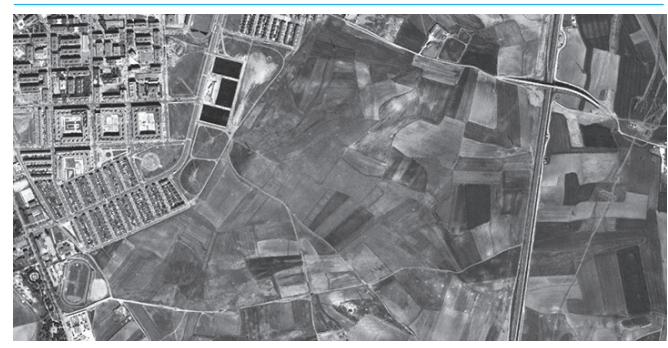

Fuente: Paisajetransversal.org. Autorización blog Abel Gil.

\section{FIGURA 10. TERRENOS INTERVENIDOS, PARLA DEL ESTE, ESPAÑA}

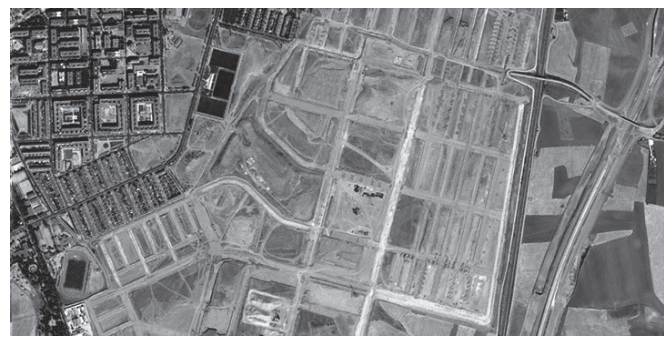

Fuente: Paisajetransversal.org. Autorización blog Abel Gil.

FIGURA 11. PARLA DEL ESTE, ESPAÑA

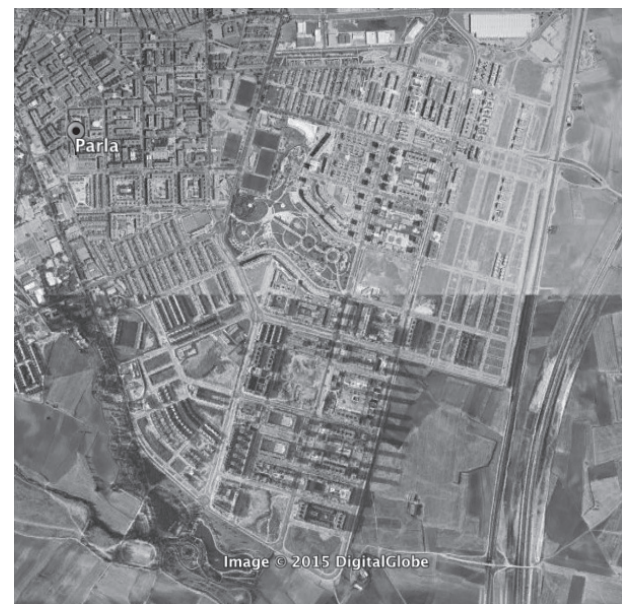

Fuente: Google Earth, 2016

OPERA, $\mathrm{N}^{0} 19$.Julio-Diciembre 2016.pp. 55-81 
...unas unidades urbanas únicas endógenas y con una alta capacidad de servir como espacios de referencia identitaria para la generación e integración de una sociedad residente, y por tanto generadores de una comunidad, garante de una buena calidad de vida (Gil, 2015).

\section{Park am Gleisdreick, Berlín, Alemania}

A mediados del siglo XIx, el corredor férreo atravesaba de norte a sur la ciudad de Berlín, Alemania. Un triángulo de intercambio donde se entrecruzaban diversas líneas y alrededor del cual se encontraban bodegas y diversos edificios, separaba los barrios de Kreuzberg al este y Schöneberg al oeste. Tras la Segunda Guerra Mundial el tren cambió de línea y este espacio, llamado Gleisdreieck -triángulo ferroviario-, se convirtió en un terreno baldío que fue invadido por la naturaleza y se convirtió en un enclave único de fauna y flora que pasaba desapercibido para la mayoría de los habitantes de la ciudad.

A comienzos del año 2000, el Museo Alemán de la Tecnología se instaló al noroeste del sector en los antiguos edificios y propuso intervenir la infraestructura existente para albergar el museo. En 2006, la municipalidad de Berlín se dio a la tarea de convertir el Gleisdreieck en un gran parque urbano e integrar los elementos existentes tanto naturales como artificiales. El parque se organizó en torno a un prado central, cruzado de este a oeste por un sendero, el cual es continuación de uno de los principales bulevares de Kreuzberg, y de norte a sur por las vías de tren.

El equipo de arquitectura y paisajismo alemán Atelier Loidl consiguió convertir este terreno invadido por la naturaleza y olvida- do, en un espacio público que articula las conexiones entre los diversos tejidos urbanos adyacentes. Además de convertirse en un pulmón de la ciudad, propicia la cohesión social.

\section{FIGURA 12. PARK AM GLEISDREIECK EN 1940, BERLÍN, DE}

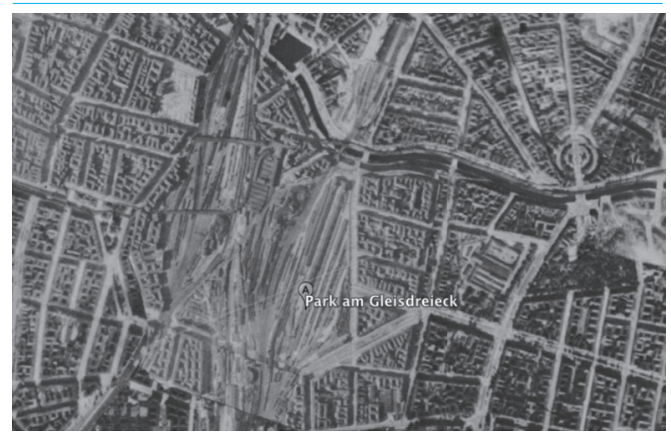

Fuente: Google Earth, 2016.

FIGURA 13. PARK AM GLEISDREIECK EN 2014, BERLÍN, DE

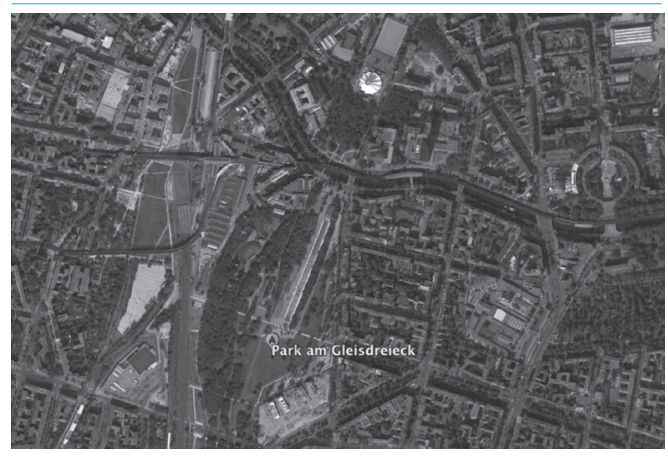

Fuente: Google Earth, 2016.

Desde 2013, el parque entrelazó las áreas verdes de la zona gubernamental y la Potsdamer Platz, para extenderse en dirección sur hasta el parque Schöneberger Südgelände. La intervención involucra un eje verde que conserva los bosques de arces, robles y 
abedules -parte de la tradición urbana-, los antiguos edificios del ferrocarril, un área de juegos y plataformas para skyboard (Senate Department for Urban Development and the Environment, 2015).

Esta redifinición de paisaje intermedio tiene su analogía con los proyectos propuestos por Olmsted a finales del siglo xIX, dándole un nuevo significado al uso y la sostenibilidad de bosques y tierras baldías urbanas. Por otra parte, la consolidación a futuro de este enclave será, ojalá, garante de la continua redefinición y reinvención de Berlín como ciudad del siglo XXI (figuras 12 y 13).

\section{Circasia, Quindío, Colombia}

El municipio de Circasia, fundado durante el proceso de colonización cafetera a finales del siglo XIX, está ubicado en la parte centronorte del departamento del Quindío, sobre la vertiente occidental de la Cordillera Central de Colombia. Dista de Armenia, la capital, 12 kilómetros y su extensión es $91,37 \mathrm{~km}^{2} ; 2,30 \mathrm{~km}^{2}$ de área urbana y $89,07 \mathrm{~km}^{2}$ de área rural ${ }^{6}$.

Circasia hace parte de los 47 municipios colombianos declarados por la Unesco como Patrimonio de la Humanidad por sus particularidades únicas como paisaje cultural cafetero. Ejemplo sobresaliente de hábitat representativo de la cultura cafetera, al incluirse dentro de la lista, debe protegerse, entre otras, de la creciente urbanización. El paisaje cultural cafetero se considera un patrimonio vivo, frágil y susceptible de deteriorarse o incluso perderse y es necesario tomar conciencia para su conservación y perduración en el tiempo.

Una jornada académica que involucró estudiantes de la Maestría en Arquitectura del Paisaje de la Universidad de Pensilvania, Estados Unidos, y la Maestría en Ciencias del Hábitat de la Universidad de La Salle de Bogotá, planteó un trabajo teórico y práctico (tanto de diseño como de proyectación), titulado "Apropiación social del paisaje cultural cafetero", con la intención de hacer propuestas e intervenciones en este territorio.

El ejercicio planteado y desarrollado por las universidades aborda, desde un análisis actual, el paisaje natural, el cultural y el crecimiento urbano proyectando a futuro sus potencialidades y opciones. Las propuestas de manera integral enfrentan el tema de sostenibilidad, sustentabilidad y control de las zonas periurbanas, e integración y recuperación de la estructura ecológica.

El ejemplo que muestra la figura 14 evidencia una continuidad del tejido urbano, un respeto desde su trazado original en forma de damero, que permite nuevas tipologías y nuevas intervenciones espaciales, siendo conscientes de la preservación de cuencas y del manejo del paisaje natural. Regenerar un paisaje cultural adecuado de manera sostenible y sustentable permite, a futuro, no solo la conservación de sus particularidades como paisaje cafetero que perfila la región, sino la generación de entornos urbanos respetuosos e integrales.

Este tipo de trabajos anticipa la intervención sobre el paisaje intermedio de manera

6 Véase http://www.circasia-quindio.gov.co/informacion_general.shtml\#identificacion 
funcional integrando aspectos del entorno inmediato con sus elementos preexistentes que le dieron sus características, y debe conservarse tanto física como culturalmente. Reconoce la necesidad del entendimiento del territorio de manera multiescalar y la interpretación de este desde la integralidad en lo físico, lo social, lo económico y lo cultural.

\section{La ciudad-región: el paisaje intermedio}

La investigación adelantada inicialmente por los profesores Oscar Grauer ${ }^{7}$ y Ximena
Samper de $\mathrm{Neu}^{8}$ sobre ciudad-región, trascendió el mero ámbito académico para lograr un encuentro de diálogo entre universidades, profesores y alumnos para abordar de manera integral el paisaje intermedio. Esta investigación pretendía, además de estudiar el crecimiento metropolitano de Caracas y Bogotá, involucrar estudiantes de estas universidades para "analizar, comparar tendencias y estudiar procesos de manejo y gestión de lo que se denomina el paisaje intermedio, entendido como el espacio ubicado entre lo urbanizado y el territorio no construido" (Universidad

\section{FIGURA 14. CIRCASIA, QUINDÍO. DISEÑO URBANO - PAISAJE CULTURAL CAFETERO}

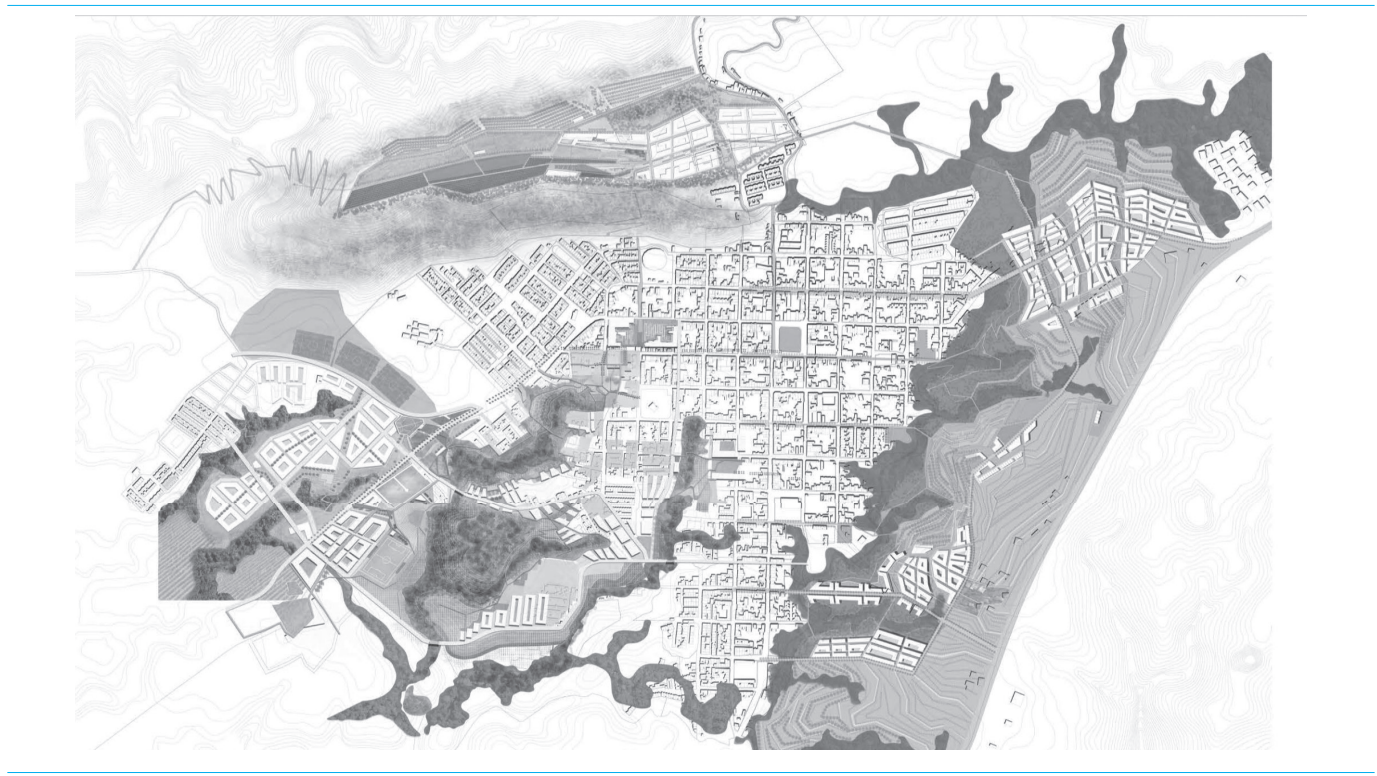

Fuente: con autorización de D. Gouverneur - U. Pennsylvania, USA.

Arquitecto de la Universidad Simón Bolívar de Caracas, Venezuela, con maestría y PhD en Diseño Urbano de la Universidad de Harvard, académico y profesor.

8 Arquitecta de la Universidad de los Andes, con maestría en Diseńo Urbano de la Universidad de Harvard. Profesora de la Universidad de los Andes y directora de la maestría de Ciencias del Hábitat de la Universidad de La Salle. 
de los Andes, Universidad Metropolitana y Harvard University, 2007, p. 8).

Los alumnos de las universidades de Bogotá y Caracas tuvieron la oportunidad de escuchar de primera mano sobre aspectos políticos, sociales, económicos, así como de gestión urbana e inmobiliaria, y políticas públicas, para comprender las diversas variables que conciernen al crecimiento y desarrollo de la estructura de las ciudades hacia sus periferias. De esta experiencia resultó el libro La ciudad-región: el paisaje intermedio. Casos de estudio: La Sabana de Bogotá - La región capital de Caracas (Universidad de los Andes, Universidad Metropolitana y Harvard University, 2007).

Cabe destacar que la aproximación que se realizó sobre el paisaje intermedio redunda en un análisis donde lo "relacional y no factual, es decir, lo importante es la relación y a través de su definición, lo construido y lo no construido adquieren significado" (Universidad de los Andes, Universidad Metropolitana y Harvard University, 2007, p. 44). El territorio debe ser entendido como un todo, y en el caso de Bogotá, es necesario pensar -en palabras del taller de diseño urbano- en la CiudadSabana y no, como se ha hecho hasta ahora, en la Ciudad en la Sabana.

Los derroteros buscaban registrar la diversidad contextual que resuelve las contradicciones y oportunidades entre lo urbano y lo rural. Ello puede verse principalmente desde la óptica urbana, cuya tendencia se ubica en los bordes y límites que impone el crecimiento urbano metido entre lo rural, anticipando el crecimiento fragmentado y exigiendo que su desarrollo sea controlado e integral a diversas escalas, para que el territorio sea entendido como un todo y no como una colcha de retazos (Universidad de los Andes, Universidad Metropolitana y Harvard University, 2007).

Los proyectos elaborados con detalles de arquitectura, manejo del paisaje y diseño urbano, y la sistematización de los trabajos, invitan a analizar los capítulos de este documento que incluye en sus títulos el ideal de cómo se debe abordar el paisaje intermedio: Tres centralidades; Proyectos de ensanche; Una ciudad a partir de la memoria del territorio; Simbiosis urbana, entre otros.

La recopilación de ejercicios y el diálogo que permitió el taller valora temas sobre sostenibilidad y sustentabilidad para remediar divergencias dentro del paisaje cultural. Es el comportamiento de condiciones de bienestar y calidad de vida desde lo socioambiental que condicionan un desarrollo respetuoso desde el medio ambiente mismo. Lo anterior, conlleva visiones de integralidad que miran territorio, paisaje, contexto como un todo, dando énfasis a lo local y a la toma de decisiones de abajoarriba (Pillet, Cañizares y Ruiz, 2010; Sánchez y Egea, 2013).

\section{North Cambridge, Boston, Estados Unidos}

Hacia 1950, Kevin Lynch, dentro de sus análisis y lectura de la ciudad de Boston realiza, siguiendo las transformaciones históricas de la urbe, un mapeo que incluye los recuerdos y la percepción de los habitantes que han empezado a vivir una ciudad que se transforma sobre grandes ejes viales. Advierte que la ciudad se desdibuja, desparece, por la aparición de autopistas que penetran, rompen, 
fraccionan y separan las zonas tradicionales históricas del centro y la parte norte, quedando vacíos o intersticios residuales. También la escala, cuyas históricas y viejas construcciones de ladrillo compiten con la aparición de rascacielos, quedan a merced de una ciudad rápida (autopistas y vehículos) que desconfigura la lenta (los suburbios), como preámbulo del paso de lo urbano hacia lo periférico (Lynch, 1984; Shane, 2005).

Hacia 1959 Lynch, con la colaboración de Meyer y Appleyard, analizan opciones de intervención que conecten por debajo de las autopistas la ciudad con el puerto, el borde costero y los barrios aledańos. Este trabajo influenciaría positivamente otras opciones como lo fueron la construcción del edifico municipal a finales de los años sesenta, abriendo una enorme plaza que ampliaba la visual y dejaba al descubierto una historia que debía ser reconocida. Hacia 1970 se inicia la rehabilitación del Quincy Market, mercado tradicional donde se renuevan edificios y áreas deprimidas con un éxito que se replica en otras ciudades. Pese a estos positivos esfuerzos de renovación, el North End, con sus restaurantes italianos, permanecía oculto tras las estructuras oscuras de la autopista. Luego de años de planeación, en 1991 se iniciaron las obras de demolición de las estructuras de la autopista I-93, dando paso a un proyecto de enorme envergadura con la construcción del Big Dig - Central Artery. Hacia el año 2000 se evidencian proyectos concretos de recuperación del espacio urbano cuando los promotores buscan conectar vacíos recuperados con la zona de la bahía, cuya arquitectura grandilocuente incita a ese nuevo zurcir de la ciudad (Shane, 2005).

Así, el Big Dig se convirtió en el programa más costoso de la historia reciente de desarrollo y renovación urbana de Estados Unidos. Incluye construir autopistas subterráneas y convertir las áreas recuperadas en la superficie en un parque lineal de grandes proporciones, con algunos edificios que cosen la ciudad nuevamente. La vitalidad de esta zona comienza a sentirse dentro de la resiliencia de un entorno urbano amable rodeado por rascacielos que dan cuenta de una ciudad vital.

Los nuevos intercambiadores viales generados, y los procesos de renovación, han permitido al sur, con la vecina ciudad de Cambridge, separada de Boston por el Charles River, nuevas conexiones de puentes, tréboles $\mathrm{y}$ accesos influenciados por la prestancia del Leonard P. Zakim Bunker Hill Memorial Bridge, imponente estructura que se ha convertido en la imagen de la ciudad. El nuevo desarrollo intraurbano ha generado intersticios y terrenos vacíos a lado y lado disponibles para el inicio de planes de vivienda, oficinas y usos complementarios, y de proyectos inmobiliarios (figuras 15 y 16).

En el transcurso de este nuevo tejido de ciudad es importante resaltar la unión y el ensamblaje de parques, paseos y zonas verdes que permiten un deambular a pie o en bicicleta desde la estación del tranvía y buses de Lechmere, que incluye el North Point Park en Cambridge, contemplando la extensión del Lederman Park al otro lado del río, para dirigirse hacia el nuevo parque en el North End y la zona conocida como Haymarket, vecino al mercado y a la zona histórica de Boston. 
FIGURAS 15 Y 16. NORTH POINT PARK CAMBRIDGE, MA
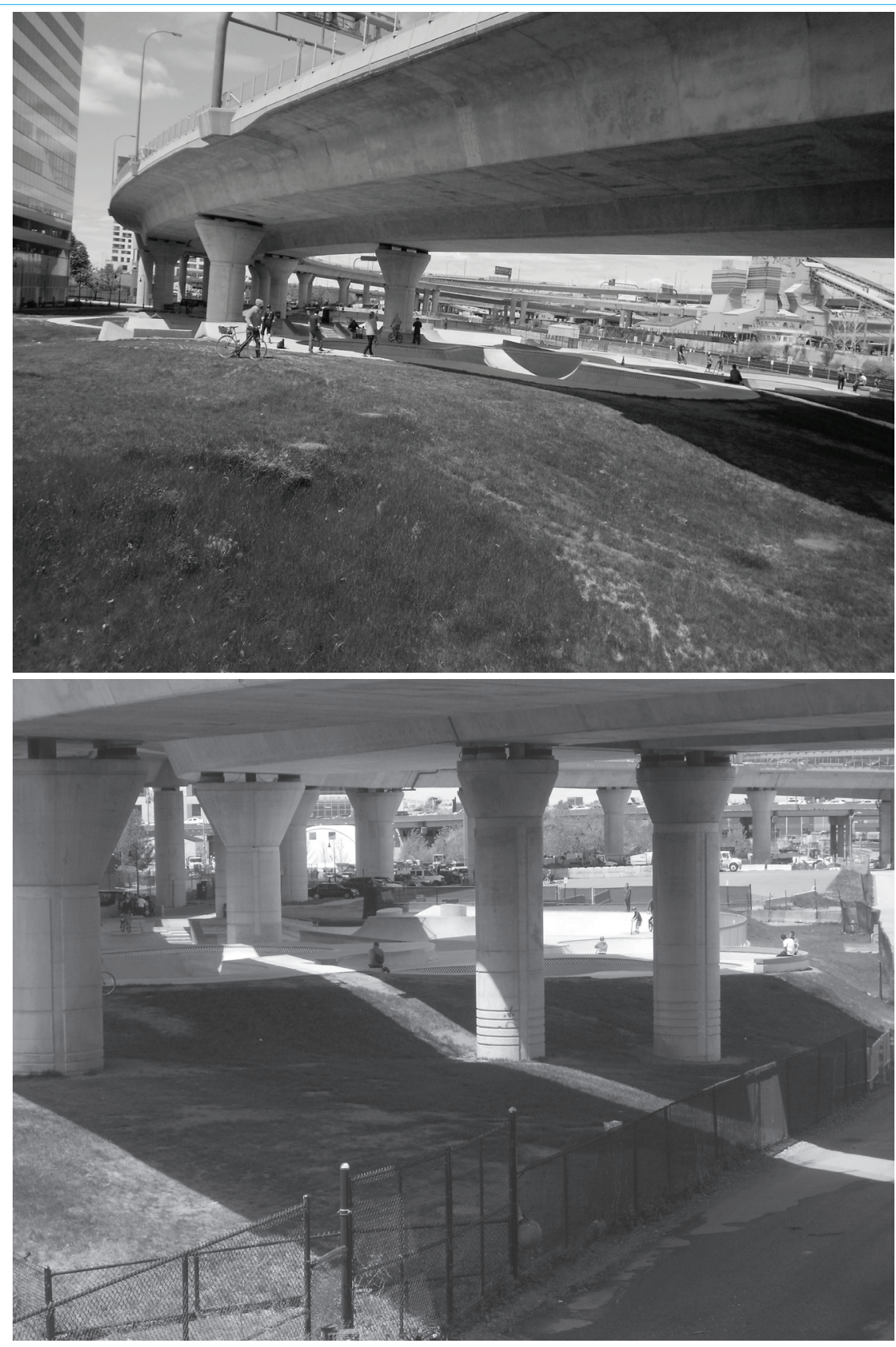
El paseo pues, se inicia sobre el borde del río y continúa hasta encontrar rampas bajo las autopistas en terrenos evidentemente sobrantes, vacíos, intersticios dejados por columnas y estructuras del intercambiador. Surgen en el trayecto zonas de amplios prados, equipamientos deportivos y recreativos, esculturas que emergen de los escombros de obra, playas y bosques urbanos en crecimiento, las esclusas del río, hasta llegar a la nueva zona del Big Dig y el North End (figura 17).

Este zurcir integrando los elementos perdidos y los nuevos, generados sobre los espacios resultantes o vacíos, es la demostración tangible y actual de la posibilidad de leer y enfrentar el crecimiento de una ciudad para intervenirla, renovando y develando sus particularidades y significados. Todos estos elementos y procesos permiten retomar la lectura de Lynch cuando afirma: "Una ciudad como esta sería una ciudad que pudiera aprehenderse con el tiempo como una pauta de gran continuidad, con muchas partes diferenciadas y nítidamente vinculadas entre sí” (Lynch, 1984, p. 20).

\section{Soportes informales (Informal Urban Armatures)}

Lynch (1984), Shane (2005) y Gouverneur (2015) plantean la importancia de generar aquello que este último autor denomina

\section{FIGURA 17. NORTH CAMBRIDGE Y HAYMARKET CON EL ZAKIM BUNKER HILL MEMORIAL BRIDGE. A LA IZQUIERDA ARRIBA ESTÁ EL NORTH POINT PARK, A LA DERECHA ARRIBA LAS ESCLUSAS DEL CHARLES RIVER Y ABAJO DERECHA EL NORTH END EN BOSTON}

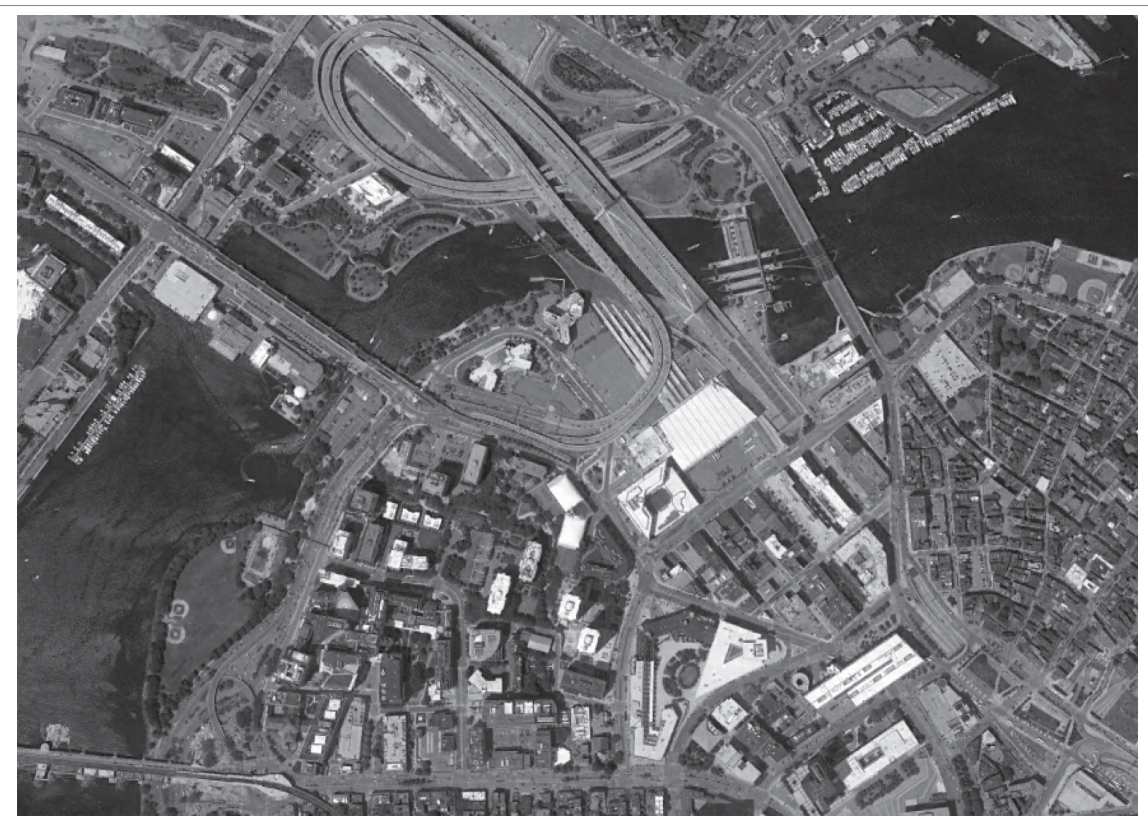

Fuente: Google Maps, 2016. 
"soportes informales", armaduras que definen ejes / corredores, campos y nodos especiales, como herramientas efectivas de aproximación para crear nuevas áreas urbanas o bien para o reajustar las existentes.

Estos soportes informales o armaduras, admitirían enfrentar el desarrollo de la ciudad para visualizar elementos urbanos y arquitectónicos -los cuales suelen estar presentes, con variaciones, en el momento de modelar la ciudad-, y podrían ayudar a mantener o propiciar el orden y estructurar espacios para dotarlos de significados. Bien lo dice Lynch: [...] "la forma de cualquier asentamiento permanente debe ser un modelo mágico del universo y de los dioses" (Lynch, 1985, p. 61), mirada que se dirige hacia el capital humano de los enclaves urbanos y la calidad de vida, ligado a la recuperación de ese prestigio de una ciudad al que nos referimos al inicio de este texto.
Gouverneur (2015) propone, para la intervención de la ciudad, acompañar el asentamiento inicial y la evolución de nuevos asentamientos informales, los cuales surgirán en las periferias de las ciudades, alejados de las centralidades, y generalmente contiguos a asentamientos informales existentes. Plantea que, de no contar con apoyo externo, en términos de planificación, diseño y gestión, los nuevos asentamientos que surgen con el crecimiento urbano resultarán igualmente de formas urbanas incompletas, enclaves aislados, al margen de los beneficios de la vida urbana, carentes de servicios, infraestructura, movilidad, espacios públicos y lugares simbólicos, los cuales ofrecen dignificación, deleite e imaginarios urbanos (figura 18).

Este método de aproximación combina los atributos de la informalidad -la flexibilidad, el dinamismo, la capacidad de transformación, la ocupación compacta del suelo, el

FIGURA 18. D. GRAHAME SHANE, RECOMBINANT URBANISM. SOPORTES TUTELARES: ELEMENTOS URBANOS Y ARQUITECTÓNICOS, LOS CUALES SUELEN ESTAR PRESENTES, CON VARIACIONES, EN EL MOMENTO DE MODELAR LA CIUDAD

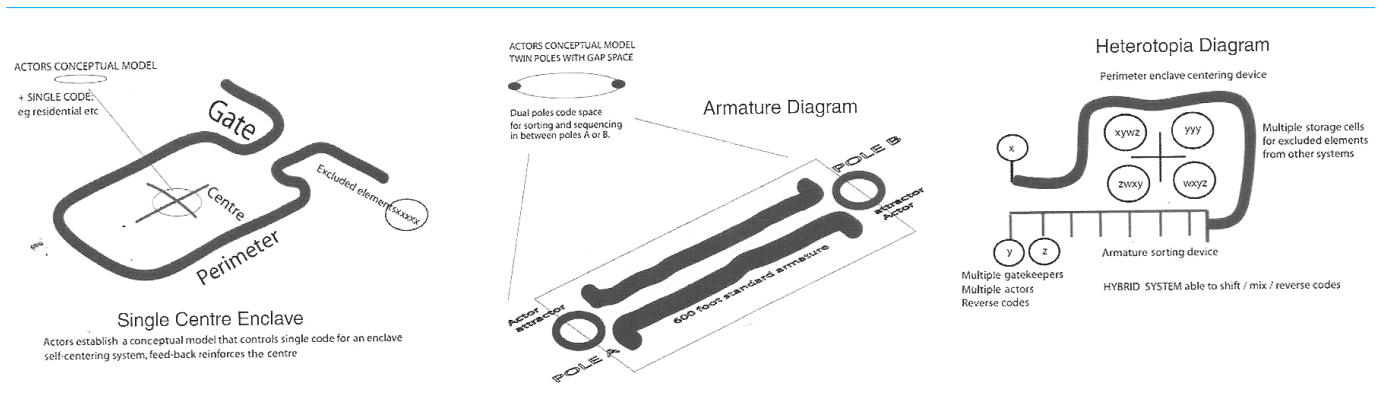

Fuente: gráfica utilizada con permiso del autor (Shane, 2005, p. 15).

9 Traducción de Informal Urban Armatures, sugerida por D. Gouverneur, autor del método expuesto en el libro: Planning and Design for Future Informal Settlements: Shapping the Self-Constructed City (2015). 
sentido de pertenencia y cohesión social-, con los beneficios de lo formal, gestionado y diseñado, para lograr así una rica ecología urbana, en proceso de constante transformación, que saca provecho de las ventajas derivadas de encontrarse en la frontera entre lo urbano y lo rural/ natural.

Estas periferias emergentes e informales pueden, entonces, ser objeto de una planificación / diseńo y acompañamiento integral, mediante sistemas de apoyo físicos y no físicos, a manera de soportes tutelares que faciliten condiciones adaptadas a las características de cada emplazamiento. Estos sistemas de soporte deben ser capaces de adaptarse en el tiempo y en el espacio, resultando en formas urbanas sostenibles y sustentables que respeten las preexistencias culturales y locales logradas a través de decisiones participativas (Rosales, 2007; Sánchez y Egea, 2013; Gouverneur, 2015).

\section{CONCLUSIONES FINALES}

Kintsukuroi es el término japonés que designa al arte de reparar con laca de oro o plata, entendiendo que el objeto es más bello por haber estado roto.

Wigand, s. f.

Este texto puede tomarse como un estado del arte que expone disímiles ejemplos y formas de enfrentar el crecimiento y la ocupación de la ciudad. Se quedan sin nombrar ejemplos como el Parc Daumesnil en París, el High Line en Nueva York, y la actual recuperación en Toronto, bajo el Gardiner Expressway que a futuro plantea rescatar el espacio bajo la estructura del viaducto e integrar barrios, actividades y población. Sin embargo, los acá incluidos se consideran proyectos originales y novedosos, que reunieron voluntades sociales y políticas de cambio; se ubicaron en lugares que no formaban parte de planes ni de procesos de ordenamiento, y anclaron propuestas con visiones diversas. Fueron franjas intermedias expectantes que generaron cambios e influyeron en las opciones presentes en las ciudades, iniciativas logradas para convertir esos intersticios que parecían invisibles en áreas donde la cotidianidad no pasa desapercibida.

El coser la ciudad se asemeja de manera analógica al Kintsukuroi, cuya trascendencia asume y aduce la importancia por mantener el tejido urbano y social de manera coherente dentro del paisaje, y como parte del entorno, de lo sostenible y sustentable; aquello que debemos preservar desde lo natural hasta o hacia lo cultural. Es un todo relacionado con el paisaje y su preservación, transformación y manutención.

Julio Muñoz (2010) en su ponencia "El paisaje: tipos y unidades" ${ }^{\prime 10}$, caracteriza y tipifica las diversas formas del paisaje y su evolución desde lo natural hacia lo cultural y aduce que los "paisajes periurbanos no construidos [...] con la finalidad de definir unidades y valorar

10 Ponencia en el marco del xxi Congreso de Geógrafos Españoles 2009. La compilación de ponencias y artículos fue editada por Ediciones del Serbal con el título Territorio, paisaje y sostenibilidad (2010). 
sus potencialidades [...] para planificar una más armónica integración" (p. 149), convierten los conceptos en algo patrimonial y social, como fundamento del ordenamiento, luego fortalecen los imaginarios, los valores, el respeto y la protección de los diversos enclaves dentro de los territorios. Es un proceso de inclusión, y de mejora que va más allá de las políticas y los planes, estrategias que facilitan intervenciones para beneficio de las poblaciones objeto o de una comunidad.

Trabajar el paisaje intermedio redunda en una labor transdisciplinar, y sin duda es una cuestión política que permite fortalecer centralidades y periferias. Para buscar potencialidades en esos espacios vacíos, las necesidades de aquellos que conviven en enclaves fragmentados, y que se beneficiarían de desarrollos sociales, comunitarios, industriales y de vivienda o de espacios lúdicos "el verde urbano cobra sentido dentro del dispositivo general para la provisión de servicios, base sustentadora de la colectivización urbana" (Tomé, 2005, p. 67).

La necesidad de abordar y concebir el paisaje intermedio como "el marco espaciotemporal que posibilita la reinterpretación de la realidad por la concentración de interacciones significativas" (Reguillo, 2005, p. 50), es un fundamento de la construcción colectiva del territorio, hace énfasis sobre los patrones de urbanización actuales que propician por un lado la suburbanización donde no se facilita "la generación y reproducción de la sociedad civil, del público en cualquiera de sus definiciones" (Treviño, 2013, p. 39), sino que prevalece la fragmentación del espacio, de la sociedad y del individuo.
Quedan criterios e ideas para debates adicionales. El paisaje intermedio es una disculpa, una herramienta, una "armadura” que debe ser tomada con esmero y de manera sistemática y sistémica para decidir su futuro. Se trata de hacer lugar basado en las oportunidades y realidades; necesidades y requerimientos para que el común de la gente perciba un significado, una pertenencia y permanencia en este nuevo enclave. Es la posibilidad de zurcir la ciudad rota, donde las estrategias de intervención se interceptan, superponen e intermedian para propiciar soluciones, cuando los actores sociales y sus territorios son considerados como los pilares y artífices de cambio. Cuando se logra demostrar que, una vez se superan las desavenencias y se encuentran derroteros comunes, las gobernanzas y actuaciones propician transformaciones significativas en lo local y en lo obvio.

La opción es fortalecer políticas públicas para acometer de manera racional la ocupación del paisaje intermedio como parte de la planificación, el diseño, la renovación, rehabilitación y revitalización del ordenamiento de un territorio. Es un problema de escala, de redensificar y de ubicar ejes, nodos y elementos tutelares como conformadores del continuum urbano mezclado con un paisaje que establece una unidad.

En cada instante hay más de lo que la vista puede ver, más de lo que el oído puede oír, un escenario o un panorama que aguarda ser explorado. Nada se experimenta en sí mismo, sino siempre en relación con sus contornos, con las secuencias de acontecimientos que llevan a ello, con el recuerdo de experiencias anteriores (Lynch, 1984, p. 9) 
FIGURA 19. HUFEISENSIEDLUNG, BERLÍN, 2016

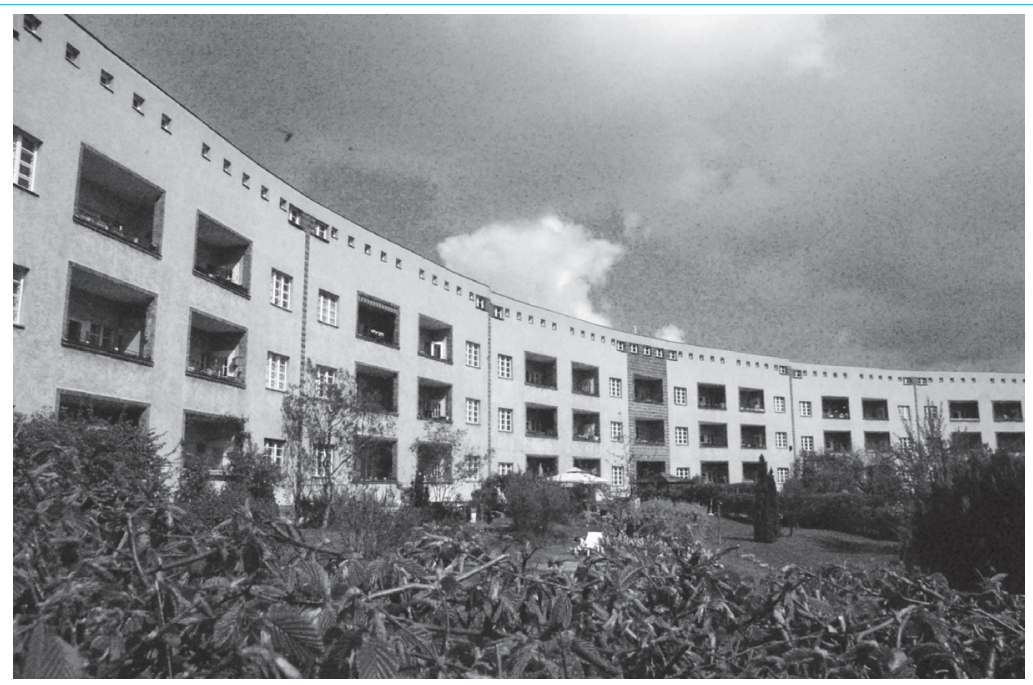

Fuente: foto del autor.

\section{REFERENCIAS}

Andrés, R. (2015). Las ciudades de la expulsión. Recuperado de http://elpais.com/elpais/2015/02/02/ eps/1422890406_491865.html

Ascher, F. (2004). Los nuevos principios del urbanismo. Madrid: Alianza Editorial.

Balbo, M., Jordán, R. y Simioni, D. (comp.) (2003). La ciudad inclusiva. Santiago de Chile: CEPAL.

Batty, M. y Longley, P. (1994). Fractal Cities - A Geometry of Form and Function. London, USA: Academic Press Limited.

Beveridge, C. y Rocheleau, P. (1998). Frederick Law Olmsead: Designing the American landscape. New York: Universe Publishing.

Blau, E. (1999). The architecture of Red Vienna - 19191934. Cambridge: MIT Press.

Borja, J. y Castells, M. (1997). Local y Global - La gestión de las ciudades en la era de la información. Madrid: Santillana.
Brenne, W. (2013). Bruno Taut - Master of Colourful architecture in Berlin. Berlin: Deutscher Werkbund Berlin.

Caloca, O., Cárdenas, A. y Ortiz, E. (2010). Costos de localización: una aproximación teórica a la economía espacial. Análisis Económico, xxv (60), 5-28.

Camagni, R. (2005). Economía urbana. Barcelona: Antoni Bosch.

Caron, D. y Martínez, A. (2008). Grupo de Pesquisa Identidade e Territorio. Recuperado de http://www. ufrgs.br/gpit/wp-content/uploads/2011/04/ caron-martinez-espacios-intermediarios.pdf

Castells, M. (1976). La cuestión urbana. México: Siglo xxI Editores.

Cousins, M. (2009). Design Quality Housing. Abingdon: Taylor y Francis.

Choay, F. (1969). The Modern City: Planning in the 19 Century. New York: George Braziler. 
Díaz Parra, I. (2013). Gentrificación y disciplinamiento en los centros históricos. En Sánchez, D. y Egea, C. La ciudad, un espacio para la vida (pp. 75-92). Granada: Editorial Universidad de Granada.

Escallón, C. (2014). Gobernanza en procesos de regeneración urbana. Bogotá: Universidad de los Andes - CIDER.

Galeano Alegría, D. G. (2011). El papel de las áreas de cesión en la configuración del sistema de espacio público de Bogotá: estudio de caso localidad de Suba [Maestría tesis]. Bogotá: Universidad Nacional de Colombia. Recuperado de http://www.bdigital.unal.edu.co/6999/\#sthash.R1gwbbUI.dpuf

García, B. (2008). Ecodiseño - Nueva herramienta para la sustentabilidad. México: Designio.

Gil, A. (2015). Los nuevos retos en la creación de ciudad: integrar los paisajes previos. Recuperado de http:// www.paisajetransversal.org/2015/03/nuevosretos-creacion-ciudad-integrar-paisajes-previosordenacion-territorio-urbanismo-planeamientourbano.html

Gómez, A. y Londoño, F. (2011). Paisajes y nuevos territorios (en red). Barcelona: Anthropos Editorial.

Gómez, A. (2010). Propuesta conceptual y metodológica para el análisis, diseño y planificación de la sostenibilidad urbana del paisaje en ciudades de media montaña andina. Experimentación en Manizales, Colombia [Tesis doctoral ed.]. Barcelona: Universidad Politécnica de Cataluña.

Gouverneur, D. (2015). Planning and design for future informal settlements. New York: Routledge.

Hall, P. (1998). Cities of Tomorrow. Malden: Blackwell Publishers Inc.

Kostov, S. (1991). The City Shaped - Urban Patterns and Meanings through history. London: Thames and Hudson Ltd.

Krugman, P. (1998). Space: the final frontier. Journal of Economic Perspectives, 12 (2), 161-174.
Leva, G. (2005). Indicadores de calidad de vida urbana. Buenos Aires: Universidad Nacional de Quilmes.

Lynch, K. (1984). La imagen de la ciudad. Barcelona. Editorial Gustavo Gili.

Lynch, K. (1985). La buena forma de la ciudad. Barcelona. Editorial Gustavo Gili.

Martí Aris, C. (2000). Las formas de la residencia en la ciudad moderna. Barcelona: Ediciones de la Universidad Politécnica de Catalunya.

Mumford, L. (1966). La carretera y la ciudad. Buenos Aires: Emecé Editores.

Muñoz, J. (2010). El paisaje: tipos y unidades. En Pillet, F., Cañizares, C. y Ruiz, A. Territorio, paisaje y sostenibilidad (pp. 139-156). Barcelona: Ediciones del Serbal.

Ordeig, J. M. (2004). Diseño urbano y pensamiento contemporáneo. Barcelona: Alvagraf.

Panadero, M. (2010). Geografía humana y sostenibilidad. Hitos y perspectivas. En Pillet, F., Cañizares, M. y Ruiz, A. Territorio, paisaje y sostenibilidad - Un mundo cambiante (pp. 49-86). Barcelona: Ediciones del Serbal.

Pillet, F., Cañizares, M. y Ruiz, A. R. (2010). Territorio, paisaje y sostenibilidad - Un mundo cambiante. Barcelona: Ediciones del Serbal.

Pizarro, R. (2001). La vulnerabilidad social y sus desafios: una mirada desde América Latina. Santiago de Chile: Cepal.

Poston, S. (1997). Place in the Middle Landscape. Blacksburg: Virginia Polyttechnic Institute and State University.

Preciado, J. (2006). Los árboles en la ciudad y la expansión de Bogotá: reflexiones para construir una calidad ambiental urbana. En Nail, S. Bosques urbanos en América Latina: usos, funciones, representaciones (pp. 25-55). Bogotá: Universidad Externado de Colombia.

Rama, A. (1998). La ciudad letrada. Montevideo: Arca. 
Reguillo, R. (2005). La construcción simbólica de la ciudad. Tlaquepaque: Instituto Tecnológico y de Estudios Superiores de Occidente - Universidad Iberoamericana.

Riener, T. (1963). The place of the Ideal Community in Urban Planning. Philadelphia: UPenn.

Rosas-Baños, M. (2013). Nueva ruralidad desde dos visones de progreso rural y sustentabilidad: economía ambiental y economía ecológica. Recuperado de http://polis.revues.org

Rosales, R. (2007). Desarrollo local: teoria y prácticas socioterritoriales. México DF: Universidad Autónoma Metropolitana.

Rowe, P. (1991). Making a middle landscape. Cambridge: MIT Press.

Sánchez, D. y Egea, C. (2013). La ciudad, un espacio para la vida - Miradas y enfoques desde la experiencia espacial. Granada: Editorial Universidad de Granada.

Salom, J. (2010). El territorio: escalas y estrategias. En Pillet, F., Cañizares, M. y Ruiz, A. Territorio, paisaje y sostenibilidad (pp. 113-138). Barcelona: Ediciones del Serbal.

Santos, M. (1996). Metamorfosis del espacio habitado. Barcelona: Oikos-Tau.

Senate Department for Urban Development and the Environment, Berlin (2015). En Feireis, K. y Hamm, O. (2015). Transforming Cities (pp. 78-79). Berlin: Jovis Verlag GmbH.

Shane, D. (2005). Recombinant Urbanism: Conceptual modeling in architecture, urban design, and City Theory. Chischester: Wiley-Academy.

Tarragó, S. (1981). Prólogo a la versión castellana. En Rossi, A. La arquitectura de la ciudad (pp. 7-40). Barcelona: Editorial Gustavo Gili, S.A.
Thompson, I. H. (2014). Landscape architecture. A very short introduction. Oxford: Oxford University Press.

Tomé, S. (2005). La ciudad socialista y la ciudad sostenible. Anales de geografía (25), 51-70.

Toro, F. J. (2013). El no-lugar como experiencia del habitar la ciudad contemporánea. En Sánchez, D. y Egea, C. La ciudad, un espacio para la vida (pp. 181-194). Granada: Editorial Universidad de Granada.

Trancik, R. (1986). Finding lost space - Theories of urban design. New York: Va Nostrand Reinhold

Trevińo, J. A. (2013). La dimensión pública del espacio urbano. En Sánchez, D. y Egea, C. La ciudad, un espacio para la vida (pp. 27-42). Granada: Editorial Universidad de Granada.

Universidad de los Andes, Universidad Metropolitana de Caracas y Harvard University (2007). Un paisaje intermedio - Dos ciudades - Tres universidades. Bogotá: Universidad de los Andes.

Waldheim, C. (2016). Landscape as urbanism - A general theory. Princeton: Princeton University Press.

Wigand. E. (s. f.). Resiliencia y Kintsukuroi: la belleza del error. Recuperado de http://www.periodicodelbiencomun.com/arte-cultura/resilenciay-kintsukuroi-la-belleza-del-error/

Zoido, F. (2010). Territorio y paisaje, conocimiento, estrategias y políticas. En Pillet, F., Cañizares, M. y Ruiz, A. Territorio, paisaje y sostenibilidad. Un mundo cambiante (pp. 87-114). Barcelona: Ediciones del Serbal. 